\title{
The development of a Critical Incident Student Team
}

\author{
Kate Stewart and the Critical Incident Student Team
}

Kate Stewart has a PhD in the field of young people and their experiences of critical incident responses. Kate has worked for many years with young people in a variety of settings; for the past six years this has been at Wanganui Collegiate as the School Counsellor. This work is informed and guided by social work practice and a steadfast belief in the wisdom of young people.

\section{Abstract}

As a response to the work I have done in the field of critical incidents in relation to young people, this paper begins with a brief discussion of resilience and the involvement of young people in decision making, particularly in this field of practice. This is followed by an overview of the ongoing development of a Critical Incident Student Team within Wanganui Collegiate. Young people's views and opinions are integral to its functioning and as such their opinions are regularly, and often informally, gathered, analysed and acted upon. The third section is an evaluation of a formal exercise.

This paper explores the development of a Critical Incident Student Team at Wanganui Collegiate in New Zealand. This school is an independent co-educational secondary school with students being aged between 12 and 18 years. There are approximately 500 students: two-thirds are boarders, two-thirds are boys and 10 percent are international students. There is a philosophy of student involvement within the school so that they are represented in a number of decision-making areas such as the Peer Support Team and the Dining Hall Committee as well as the Critical Incident Team. This is based on a belief that what the students have to offer is worth listening to, and acting upon.

The first section gives an overview of the standing of young people's voices in schools and, more specifically, these voices in the area of critical incident responses.

\section{The voices of young people}

My $\mathrm{PhD}$ research was based on redressing the lack of young people's voices in the field of critical incident responses. The outcomes indicated that there was much wisdom and thought that young people were able to contribute. They contributed by identifying and adding depth to a number of specific areas where they believed they had valuable input to offer. These areas were:

- The need for adults and experts to be careful with the words they use when dealing with critical incidents.

- The need for schools to develop a culture of care.

- The need for schools to react proactively when a critical incident has occurred. 
- The characteristics of the people they believed were helpful in such situations and the ones that were not.

- Their own perception that young people are resilient as they deal with critical incidents.

- The need for young people to be involved and to have their voices heard.

Those interviewed felt that they had some suggestions and wisdom to offer, but that often there was nowhere to contribute them in order to influence the responses that were being offered. As well, other young people have challenged their relatively powerless position as Jamison and Gilbert (2000, p.183) report:

Decisions about 'best interests' need to be based on good information about what is going to advance children's welfare, including children's views on the matter. 'You listen to me, I know what is best for you', but we're thinking we know what is best for ourselves.

Further to this, Kiri Lightfoot, a 19-year-old young person's advocate (cited in Ministry of Youth Affairs, 1999; Preface) said that:

Being young is about testing how far you can push the boundaries and explore different things, different attitudes, different styles, different ways of living, and sometimes this can mean exploring negative things like drugs and alcohol. When things go wrong, it can seem like we don't have the coping skills to deal with them. When the present and the future are scary and unsteady it can be hard to know where to turn and how to make the next step.

Ungar (2004, p.127), has specifically researched young people in the area of adversity and resilience and indicates that developing their voices leads to a sense of power with a beneficial outcome:

They (adolescents) have argued that their capacity to experience power in the social discourses that define them is the most important determinant of their ability to overcome adversity and the risks posed to their mental well-being.

While there is a considerable amount published about the developing role of young people's voices being added to the decisions that affect society, there has been very little published in the area of these voices in relation to critical incident responses. There has been a dearth of consultation with young people to ascertain whether the responses provided by adults and experts are, in their opinion, effective. An international literature search was conducted with little success. At the national level contributions were found from Dale (1992) and Ridling (1995). Ridling (1995, p.14) commented:

Whereas staff reported that students were offered support in three cases the students felt little attention was paid to the difficulty of their daily functioning in the school context.

If this lack of data indicates that this situation is representative of what consistently happens then, potentially, the long-term effect is to have disenfranchised young people. While not talking specifically about critical incident responses, Lerner (cited in Ungar, 2004; p.81) adds that this state of being disenfranchised points to a situation where:

The set of beliefs and feelings about ourselves leads us to feel that we will lose, that we will be isolated, that other people won't listen, and that in turn leads us to act in ways in which these very fears turn out to be true. 
Seeing, and hearing, young people as who they really are as individuals becomes important if we desire more positive outcomes for them. After nearly 20 years of working with young people I have learned that when we are able to enter their reality and more fully engage with them, more positive results are engendered. As Ungar (2004, p. 302) writes:

When we step outside our adult-centric bias and look more carefully at today's youth we see much more than copycat Columbines, the drugs, the media-hyped violence, and all the other symbolic representations of a valueless, immoral youth culture. Even for the most dispossessed youth, this monochromatic picture does not reflect their reality.

With this underpinning belief that young people's voices are valuable and need to be developed in order to make a positive and constructive contribution to our society, it seems congruent to apply it to the school where I work as a school counsellor. The inclusion of students in groups is wider than the Critical Incident Student Team, but this team remains the focus of this paper. The team had its genesis in 2004. What follows is a summary of its evolution.

\section{4: Early development of the team}

In 2004, as a direct result of the findings I was encountering within my PhD research, I consulted with the School Chaplain/Director of Student Welfare on the importance of having a Critical Incident Team that was fully functioning and educated about how to respond to adverse events. Those interviewed for the research had identified some negative personal reactions when there had been incidents in their schools: they had felt powerless, that noone cared, that they were not listened to and that they were not part of any responses that were provided. There had been a strong feeling that young people had information and ideas and could positively contribute.

As a result, a group of students was brought together with the intention of educating them about critical incident responses and the existing policy. This policy had been sitting in the school policy manual for some time as a Ministry of Education requirement. The intention was to ensure that it became a working document that was readily accessible and that a number of people within the school would be familiar with it.

The initial group was made up of:

- The two school counsellors (now only one).

- An executive member who was also a Housemaster.

- A staff representative.

- The Chaplain/Director of Student Welfare.

- Six students (one from each boarding house).

The aim was also to ensure that the structure of the group was made as flat as possible, always acknowledging the historically hierarchical nature of schools such as Wanganui Collegiate. This goal was nurtured in several ways: first names for everyone (while simple this gave a clear message), the opportunity for the seniors involved to continue with the school's aim of expressing themselves assertively and effectively, ensuring that the students were making meaningful decisions and not rubber stamping decisions that had already been made, ensuring that the adults were facilitators and that decisions were group ones. 
This group spent the year doing a lot of hard work as a result of going through the policy. We found that it needed some amendments to make it applicable to Wanganui Collegiate in the 21st century. By the end of the first year the policy was in a solid redrafted format and a discussion was held as to how to hand over to the team in the following year. This team decided that, again, each House would have a representative who was a volunteer and interested in working on this committee. In reality, when it came to the beginning of 2005 those on the group were a mixture of volunteers and those who were co-opted by their Housemasters.

The previous year this team had been given the mandate to be the working group on critical incidents in order to revamp the policy. This new group began the year by going through the draft policy. As this developed it became clear to the adults on the group that, because of the questions being asked, we needed to be very clear about the role of the students when a critical incident occurred. This became built into the policy so that all involved understood that the students in the team were not to be frontline workers. That role was to be taken by the management of the school who would co-opt members as necessary.

The student group, however, was seen as a conduit with two very important roles to play:

- They were to be a line of communication from the School Critical Incident Team that was managing the incident back to their Houses.

- They were to be the 'ears' of the House so that any troubling observations, rumours, events were relayed back to the working group. This had developed from my previous experience and research where it became obvious after several incidents that the students knew different stories to the adults and often these are things that need to be known e.g. séances, students drinking and running away.

Every year this second point has been discussed with students who have asked questions that reflect that they feel like they might be 'narking' if they report on worrying student activities. As they explore what it really might mean they have always come to their own conclusion that it is a safety issue and that the role they are taking on is one of leadership with its incumbent expectation of caring for others.

\section{5: Important developments}

At the beginning of 2005 I suggested that undergoing a mock exercise would be a useful activity so that students and staff on the team received a realistic idea of the complexities of an actual incident. Up until then the group had relied on theory and policies that, while necessary, were not helpful in exemplifying the process that could be expected. As a result the Chaplain/Director of Student Welfare did a very good job of presenting a graduated critical incident that could easily be a real life scenario for the students.

Concomitant with this, a critical incident kit was put together so that everything that could conceivably be needed at the time (paper/pens / phone/stapler/white board markers etc) was in one easily accessible place. With each practice or event where it has been used, more things have been identified and added so that now we trust it is a very useful resource.

The use of the scenario was made as realistic as possible so that the students would get an overall idea of what the School Critical Incident Team responding to the incident 
would be dealing with. They were gathered in the Boardroom, the critical incident kit was made available and the policies and flowcharts were displayed on the wall. The group was walked step-by-step through the incident (a bus crash of a netball team) as we drip fed them information as would happen in a real incident. They were asked about the steps that they thought needed to be taken by the adults involved at this level. It was also carefully reiterated that this was not where they would be based and that their role involved the two important tasks previously outlined: being a conduit between the team and the students, and being a safety net for students.

At the end of the first practice run-through of the scenario we went over the exercise and did a detailed analysis of what we had missed in our planning: such as any deficiencies in the policy itself, the kit and the flow charts that the team had developed. Examples of these were:

- The need to record and track everything.

- The need for standard written messages to go to Houses (relying on word of mouth was too risky).

- The need to look after the team.

- The need to have consistent link people who could easily be contacted.

- The need for a briefing and a debriefing on a daily basis.

A practical development that came from this was the need to advertise the team and the nature of critical incidents. A prepared statement was put together that could be read to each House to make them aware of the team. This was also laminated onto bright orange paper and put on the House notice boards so that the names of team members for each House were clearly displayed.

\section{6: Further development}

In 2006 it became clear that we needed to have a plan of how the team would operate each year and what we needed to accomplish. The following were identified:

- At the end of the previous year the year 13s were encouraged to bring along a year 12 so that they could be inducted into the group in order to have a smooth transition the following year.

- In Term one the group would be introduced to the nature of critical incidents and their role within that.

- Later in Term one the mock exercise was conducted to give the reinforcement needed to ensure that the team understood the nature and importance of their job.

- The rest of the year involved one meeting per term with a topic of interest to be discussed to keep their education and their interest alive.

- The final meeting was to ensure that there was hand over.

\section{7: Real-life practice}

At the beginning of 2007 there was a smooth transition and the year started as planned. We had two incidents in the course of the year that were both low key enough to put our policy and training to the test. 
The first incident involved a university student who was assisting at Aramea, an outdoor education camp that involves all of Term two for year 10 students in the school. She had a biking accident that left her in a coma for some weeks. It was deemed essential that the school make a response and so a critical incident management team was called together. At the same time the student team was gathered. In reality, the students were not required as there was not much reaction from the student body who were not involved in Aramea and who did not know the injured university student. However, it did highlight a very important omission: we did not know how to call the student team together in a hurry in an emergency. On discussion with them we decided that we needed a copy of each of their timetables in order to speed this process up. We also considered the possibility of texting them, but as this went against school rules we decided this was not an option.

The second incident involved the sudden death of a student at another school who had connections with our school. The response went much more smoothly although contacting students by using their timetables was not put to the test. As it happened they were all in Big School (assembly) and so were asked to stay behind at the end. Again they were not needed to any great degree, but it was another trial run for the team.

Another development during 2007 was practising the scenario with the management team so that they had a working and practical knowledge of how an incident might unfold but also to familiarise them with the policy. The aim is to make this policy a living and working document in order to ensure that the implementation and outcomes of any real response is optimised.

Further to this, some consideration has been given toward the development of a parent liaison team. Because parents are integral to the school, and because at the time of an incident will always be involved, it was thought useful that a team be formed to co-ordinate parents' activities to enable these to be streamlined along with the student and management activities. There is now a PFA (Parents and Friends Association) representative on the student team who is active in thinking through how this role would be used at the time of an incident.

\section{Young people's wisdom}

Another event in 2007 was that as part of my PhD research, I needed to put together a Focus Group to critique the findings from my research. The students who opted to take part in this formed a central part of my research because their training, analysis and wisdom that had come from being part of the team offered some very valuable insights. One that was particularly important was concerning the use of language. The students challenged both the use of critical incidents and traumatic incidents as terms because they believed such language 'upped the ante' and potentially made an incident more serious than it might otherwise be. They were firmly opposed to 'traumatic' as a word because of what they perceived as negative implications of trauma. They suggested that we still use 'critical' but in the sense that is critical to get the process right.

\section{8: The next step}

The 2008 year began with a new development. The school management decided that all Heads of House would be a part of the Critical Incident Support Team. This was to acknowledge 
the importance of having those in leadership roles on the team and it was also because the school had witnessed the value that those involved had added. There were also a small number of senior volunteers who wanted to take part. There was an expectation from the team that they would enlist other seniors into a more informal role within the six Houses so that more people were informed about the role. It was envisaged that another part of the task for the Heads of House would be to hand over to the new Head of House for the following year as soon as this person was made known.

Students at the school are regularly surveyed about a range of issues: the Peer Support Group, for instance, collects opinions from students in areas such as relationships and bullying. Results are always collated and the pastoral care team will go through and discuss and act on suggestions as deemed appropriate. This is often done with input gained from the students on the respective groups. Consequently, the group of young people that made up the team of 2008 was asked four questions so that their opinions about the team could be ascertained. The difference in this year was that there was no choice about being part of the team. Therefore, all Heads of House, as well as the others who volunteered to be part of the team were surveyed. There were eight responses in all and these have been collated to give an indication of their views about being in the team.

\section{What is your opinion about being part of the Critical Incident Student Team?}

There was a range of answers here from those who questioned their role to those who thought it was an indispensable role for students.

I believe it is great to be a member of the team 'cause you are able to actively support your community with the work of the team in case of an incident.

In case of an incident that would affect students etc I think that having a critical incident team could be really important. That is why I am happy to be involved with this group as Head of House. It seems as if we should step up and be involved.

I can see what is trying to be made of the group but I don't feel we are fully aware of the importance etc of it.

\section{How do you see your role?}

Again there was a range of opinions about the role and these straddle both ends of the continuum.

I don't know what I'm supposed to be doing to be honest.

Not that important in the scheme of things,

To

Theoretically, I'm the one that brings the information from the team to the students and am around to answer and help students and forward them to help in case it's needed.

I see it as a person who can help out as a representative of the Critical Incident Team to the student body. A person who spreads correct information rather than Chinese whispers. 
What do you think students need at the time of a critical incident?

All the responses given are included here as they all give a slightly different perspective on the question.

Close observation in order to see how they may be affected, people to turn to if they have questions / worries / are not coping well. It is important that these people are people that can be trusted by the students.

The main thing is that they get the care they need as an individual.

Reassurance to understand and someone/something to calm them down.

Consolement [consolation].

To be informed.

Week off school to go home.

Depending on the type of incident, I think students need to be around people they trust, be comforted, and feel like they are in a safe environment.

Someone who will listen to them, someone who knows exactly what has happened and who can provide them with an accurate explanation, a person who can offer them advice and guidance regarding 'where to from here?'.

\section{What involvement should students have in school to ensure their voices are heard?}

This was interpreted in two ways by the students: in relation to critical incidents and in the wider sense. In the first instance those who responded thought that being part of the Critical Incident Student Team was one way of fulfilling the need for involvement. Another suggested that it needed a presentation in assembly so that the whole school understood that the team is there and that it has a voice.

When looking at the wider picture the following suggestions were given:

Forums where they can voice their opinions? Possibly student representatives.

The amount of involvement depends on every individual student. Everybody who would like to introduce changes and contribute to the school society should have an opportunity to turn to adults who can support them in their initiative.

To ensure voices are heard, there needs to be someone around who will listen to people, for example, a Head of House, prefect, tutor etc. I think Collegiate offers the right kind of people who are always there to notice students and who will lend an ear to any issues.

These answers provided many further lines for discussion with the students and more questions, for example:

- What is the school doing right?

- Is the Critical Incident Student Team giving enough information if the students are unclear about their role?

- Is the team well known enough in the school? Is there a place for student forums? A student council or advisory panel? 
It was reassuring to read the depth of their thinking about their role and also that there are young people within the school who are happy with the direction that is being followed. One commented that we just need to be doing: 'The same as we' re doing now'.

\section{Conclusion}

The involvement of students in the area of critical incidents, at all levels, within the school has been one where the students contribute at a mature and positive level. The staff is also reassured that the care of students is paramount as another layer of safety and security is put in place.

This is a work in progress and 2009 presented its own challenges and developments: we have experienced an incident that has been very personal to the school where we nearly lost a student after a rugby injury. The student team was tested over a number of days. Their debriefing was recorded, with their permission, and I will be writing a paper on their response to this event as soon as the reflection and analysis has been completed.

\section{References}

Dale, A. (1992). Management of death in school. New Zealand Journal of Counselling, 14(1), $24-31$.

Ministry of Youth Affairs. (1999). Guidelines for primary care providers - Detection and management of young people at risk of suicide. New Zealand: Ministry of Youth Affairs.

Jamison, A. \& Gilbert, L. (2000). Facilitating children's voices in the community and government. In A. J. Smith, N. J. Taylor, \& M. M. Gollop (eds.). Children's voices: Research, policy and practice. New Zealand: Pearson Education.

Ridling, L. (1995). Traumatic death in secondary school. Journal of New Zealand Counselling, 17(1), 8-16.

Ungar, M. (2004). Nurturing hidden resilience in troubled youth. Canada: University of Toronto Press. 